OPEN ACCESS

Edited by:

Jorn Toftum,

Technical University of Denmark,

Denmark

Reviewed by:

Weirong Zhang,

Beijing University of Technology,

China

José Joaquín Aguilera Prado,

Technical University of Denmark,

Denmark

${ }^{*}$ Correspondence:

Ali Ghahraman

ghahramani@nus.edu.sg;

alighahramani89@gmail.com

Specialty section:

This article was submitted to

Indoor Environment,

a section of the journal

Frontiers in Built Environment

Received: 17 July 2019 Accepted: 27 March 2020

Published: 28 April 2020

Citation:

Ghahramani A, Galicia P, Lehrer D, Varghese Z, Wang Z and Pandit Y (2020) Artificial Intelligence for Efficient Thermal Comfort Systems: Requirements, Current Applications and Future Directions.

Front. Built Environ. 6:49. doi: 10.3389/fbuil.2020.00049

\section{Artificial Intelligence for Efficient Thermal Comfort Systems: Requirements, Current Applications and Future Directions}

\author{
Ali Ghahramani ${ }^{1,2 *}$, Parson Galicia ${ }^{2}$, David Lehrer ${ }^{2}$, Zubin Varghese ${ }^{3}$, Zhe Wang $^{4}$ and \\ Yogesh Pandit ${ }^{3}$ \\ ${ }^{1}$ Department of Building, National University of Singapore, Singapore, Singapore, ${ }^{2}$ Center for the Built Environment, \\ University of California, Berkeley, Berkeley, CA, United States, ${ }^{3}$ Ingersoll Rand Engineering and Technology Centre, \\ Bengaluru, India, ${ }^{4}$ Building Technology and Urban Systems Division, Lawrence Berkeley National Lab, Berkeley, CA, \\ United States
}

In buildings, one or a combination of systems (e.g., central HVAC system, ceiling fan, desk fan, personal heater, and foot warmer) are often responsible for providing thermal comfort to the occupants. While thermal comfort has been shown to differ from person to person and vary over time, these systems are often operated based on prefixed setpoints and schedule of operations or at the request/routine of each individual. This leads to occupants' discomfort and energy wastes. To enable the improvements in both comfort and energy efficiency autonomously, in this paper, we describe the necessity of an integrated system of sensors (e.g., wearable sensors/infrared sensors), infrastructure for enabling system interoperability, learning and control algorithms, and actuators (e.g., HVAC system setpoints, ceiling fans) to work under a governing central intelligent system. To assist readers with little to no exposure to artificial intelligence (Al), we describe the fundamentals of an intelligent entity (rational agent) and components of its problem-solving process (i.e., search algorithms, logic inference, and machine learning) and provide examples from the literature. We then discuss the current application of intelligent personal thermal comfort systems in buildings based on a comprehensive review of the literature. We finally describe future directions for enabling application of fully automated systems to provide comfort in an efficient manner. It is apparent that improvements in all aspects of an intelligent system are be needed to better ascertain the correct combination of systems to activate and for how long to increase the overall efficiency of the system and improve comfort.

Keywords: machine learning, personal thermal comfort, data mining, human building interactions, buildings energy efficiency, intelligent personal comfort systems

\section{INTRODUCTION}

Indoor environments have become humans' dominant habitat as we now spend more than $90 \%$ of our time indoors (Klepeis et al., 2001). The health, well-being, and productivity of building occupants depend on four aspects of indoor environmental quality (IEQ): (1) thermal comfort, (2) visual comfort (3) acoustics, and (4) indoor air quality (Frontczak and Wargocki, 2011). 


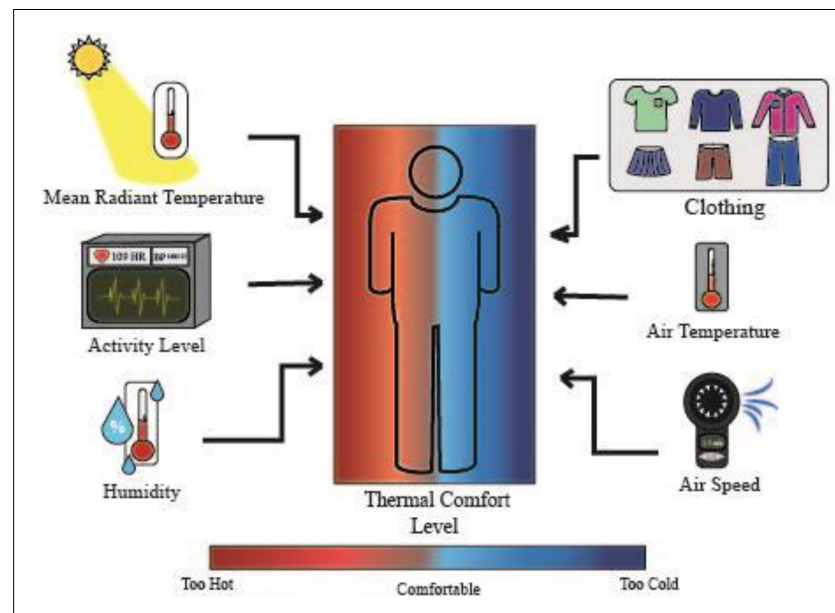

FIGURE 1 | Six factors contributing to occupant thermal comfort in Fanger's (PMV) model.

Of the four categories, thermal comfort has been shown to be a dominant factor. Studies have shown that thermal comfort is related to occupant productivity (Wyon et al., 1979; Lan et al., 2010; Arif et al., 2016). For example, it has been shown that occupant cognitive performance decreases due to the underarousal (i.e., lack of physical activation of an individual's willingness to act) caused by an increase in indoor temperature (Provins, 1966). The results of these explorations underline the importance in monitoring occupant thermal comfort, as this can lead to better, more efficient ways in which we can regulate indoor thermal conditions, potentially improving occupant cognition and productivity. Potential energy savings of using comfortdriven and energy-aware HVAC system operations vary based on the building size, type, construction materials, and climate in the range of 4-32\% (Masoso and Grobler, 2010; Vakiloroaya et al., 2014; Ghahramani et al., 2015a, 2016b; Ghahramani and Dutta, 2018). The fact that HVAC systems account for up to $10-20 \%$ of the total energy consumed in the developed countries (PérezLombard et al., 2008) make thermal comfort-driven HVAC operations an opportunity for energy savings and productivity and well-being improvements. It is interesting to note that often more than $20 \%$ of occupants experience thermal discomfort in buildings (Mishra and Ramgopal, 2013).

With the rapid growth of thermal comfort sensing technologies (e.g., wearable and infrared sensors) and operational systems (e.g., ceiling fans and personal comfort devices such as desk fans and foot warmers) in the built environments, new opportunities for providing thermal comfort to building occupants in real-time and closed-loop manner are emerging (Jung and Jazizadeh, 2019). In this paper, we present the potential of artificial intelligence (AI) for regulating thermal comfort in occupied spaces by improving functions of operational devices. To assist readers with little to no exposure to AI, we present a broad overview of the field, namely, the fundamentals behind search algorithms, logic, and machine learning, to provide enough conceptual groundwork for the reader to grasp the arguments of the paper. We then introduce a two-tiered categorization of building systems based on their extensive usage of operational technologies affecting thermal comfort. We then formulate the needed requirements before AI can be properly integrated, present some of the current applications of intelligent agents/systems, and deduce possible improvements in functionality of the operational devices through AI based on a comprehensive review of the literature. This study brings attention to the needs for further development of operational devices found in occupied spaces to better provide building occupants more comfortable thermal environments.

The organization of the paper is as follows. Section "Thermal Comfort Research, Air Conditioning, and Personal Comfort Systems Background" outlines previous research on thermal comfort and the relevant evolution in systems regulating thermal comfort. Section "Artificial Intelligence for Thermal Comfort Requirements" broadly covers the field of AI in the context of achieving occupant thermal comfort, which include general terms and concepts of AI needed to understand the technical explanations in this review. Section "Current Applications and Requirements of Artificial Intelligence for Thermal Comfort in Buildings" introduces the current applications and the respective requirements of $\mathrm{AI}$ for efficiency and control of thermal comfort in our two focus system classificationsdisjointed systems (i.e., lacking technological connectivity and full observability of the environment) and connected systems (with automation of building system management via AI) based on a comprehensive review of the literature. Based on the review, Section "Future Directions for Enabling Autonomous Personalized Thermal Comfort Systems" provides some future applications and improvements of AI within each classification. Finally, Section "Conclusion" provides a succinct summary of the comparative review of how AI improves the thermal condition of occupants.

\section{THERMAL COMFORT RESEARCH, AIR CONDITIONING, AND PERSONAL COMFORT SYSTEMS BACKGROUND}

\section{Thermal Comfort Research}

Previous research on the relationship between environmental warmth and human comfort, later described as thermal comfort, has been carried out as early as the 1930s (e.g., in the book Bedford and Warner, 1939; Zagreus et al., 2004), but it was the results of Prof. Povl Ole Fanger's research in his 1970 publication of "Thermal comfort; Analysis and Applications in Environmental Engineering" that created the basis for further exploration of thermal comfort in buildings. Fanger's extensive findings introduced the predicted mean vote (PMV) and predicted percent dissatisfied (PPD) models, which generalized the assessment of thermal comfort by introducing and relating factors (i.e., activity level, clothing, air temperature, mean radiant temperature, air velocity, and humidity) that affect thermal comfort (Figure 1) to an equation that quantifies the thermal sensation perceived by building occupants (ASHRAE Standard 62-2001, 2010). 


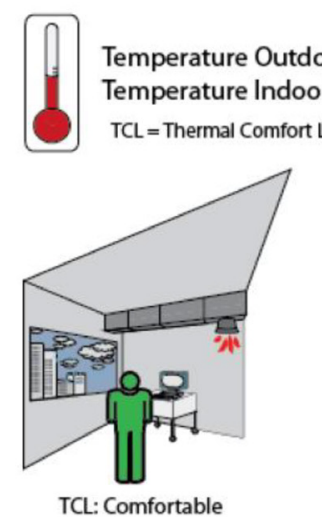

Temperature Outdoors: $16 \mathrm{C}$ Temperature Indoors: $24 \mathrm{C}$

$\mathrm{TCL}=$ Thermal Comfort Level

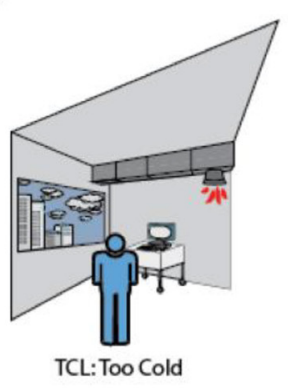

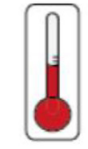

Temperature Outdoors: $30 \mathrm{C}$ Temperature Indoors: $26 \mathrm{C}$

$\mathrm{TCL}=$ Thermal Comfort Level
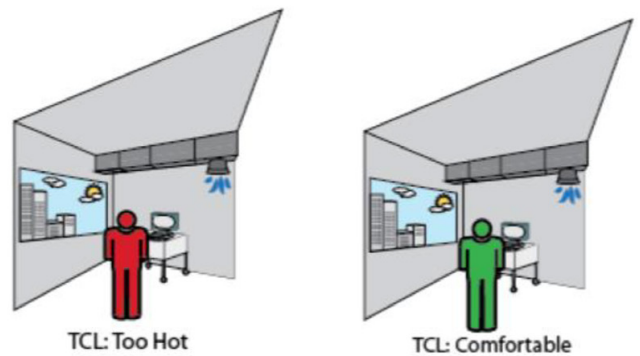

FIGURE 2 | Building occupants experience different thermal comfort preferences under similar environmental and physical conditions.

Even though the heat balance (PMV/PPD) models are regarded as the conventional method for analyzing thermal comfort in centrally controlled heating, ventilation, and air conditioning (HVAC) systems, it fails to describe thermal adaptation over time (e.g., adaptation in naturally ventilated buildings). Through further research, more recent models (e.g., adaptive models) were proposed to take into account climate variations for estimating occupants' thermal sensations (De Dear and Brager, 1998). As adaptive models are based on outside temperatures, they performed better than conventional PMV models in assessing thermal comfort in naturally ventilated buildings. The adaptive model presented by De Dear and Brager (1998) proposed a fundamentally different approach in the study of thermal comfort by suggesting a method geared toward analyzing human characteristics and tendencies in order to assess their thermal comfort. In order to gain a better understanding of occupant thermal comfort, they suggested a model that considers three types of factors that affect thermal comfort: physical (i.e., using operable windows, fans, doors, etc.), physiological (i.e., acclimatization), and psychological (i.e., the occupant's temperature expectation of the local environment) (De Dear et al., 2013). Figure 2 visualizes the argument that despite a more realistic approach in studying thermal comfort and more flexibility in real world applications, adaptive models do not address personal differences in thermal comfort as Both PMV-based and adaptive models have been developed based on responses from large groups of people. Several static and dynamic factors that influence occupants' satisfaction with their thermal environment are not used by these two models. Static factors (e.g., race, gender; Karjalainen, 2012) are independent of time while dynamic factors (e.g., acclimation, age, and food intake; Brager and de Dear, 1998; Schellen et al., 2010; Uğursal and Culp, 2013; Ning et al., 2016) contribute to the change in thermal comfort over time.

Neither the two competing principles of the heat balance models nor empirical models are capable of fully addressing these static and dynamic factors because the accuracy and consistency of both models change over time and within the context of different environments. These models consider occupants' thermal comfort largely with respect to the environment and little, if at all, with respect to their individual characteristics (i.e., acclimations, past experiences, etc.). Due to the subjectivity of thermal comfort, practitioners have typically used surveys (e.g., through user interfaces; Zagreus et al., 2004) where continuous feedback is required from the occupants. Despite accurately capturing the thermal comfort of an individual via the survey method, this approach may induce survey fatigue among participants, leading to increasing uncertainty of subjective votes (Wang J. et al., 2018), and making it arguably inefficient and time-consuming. Since occupants' comfort may differ significantly throughout short periods of time due to experiencing transient (coming from a hot or cold environment) and steady-state (occupying a relatively fixed ambient conditions indoors) conditions and the fact this information is not effectively collected (red arrows in Figure 3), buildings are not responsive enough to always meet occupants' preferences. There are several literaturereview articles which have focused on the methodology, results, and their shortcomings of the major articles in the field (Kim et al., 2018; Wang Z. et al., 2018; Jung and Jazizadeh, 2019). However, the problem of effective communicating of personal comfort information still remains an open area of research.

\section{Air Conditioning and Personal Comfort Systems}

Before the adoption of HVAC systems, thermal comfort was managed through natural ventilation and other passive strategies. Operable windows were used to manually regulate airflow in building environments by changing the airflow in and out of the building. Similarly, window shades permit users to regulate their preferred exposure to solar heat. Despite the environmentally conscious approach of natural ventilation to achieve thermal comfort, these buildings cannot flexibly function in different climatic regions with extreme weather conditions as allowing inflow of wind or exposure to sunlight from the 


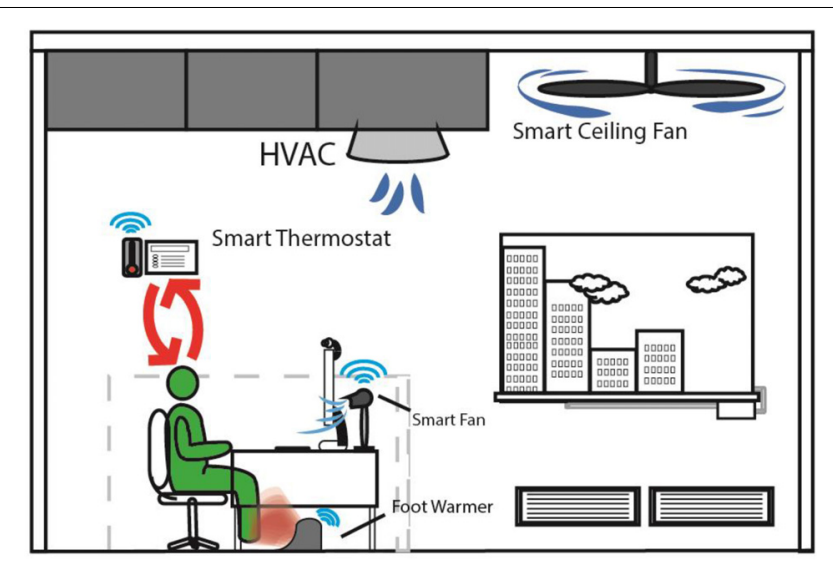

FIGURE 3 | Personal thermal comfort communication gap preventing systems in an environment to be responsive.

outside may instead provide discomfort. In addition, naturally ventilated buildings do not have the capacity to evenly distribute a comfortable temperature throughout the space causing occupants to experience temperature extremes, from intense cold to intense heat, as both the most desirable and undesirable temperature changes may occur near the source of the natural ventilation. To address the heterogeneous indoor temperature distribution of naturally ventilated buildings, centrally controlled HVAC systems were developed. HVAC systems (Figure 4) are often configured with time-invariant setpoints derived from thermal comfort standards, such as the ASHRAE Standard 55, in an attempt to monitor and regulate even temperature distribution throughout an occupied space to maintain thermal comfort for at least $80 \%$ of its occupants (ASHRAE Standard 62-2001, 2010). Operating as a responsive tool, HVAC systems are typically connected to thermostats and activated in response to changes in temperature. Through an interconnected network of ducts and vents (as depicted in Figures 4, 5), HVAC systems act reactively to maintain indoor temperatures within a comfortable range in the context of outdoor temperatures.

However, the broad application of HVAC systems undermines its overall accuracy as the physical configuration of the occupied space (i.e., placement of different furniture) and inefficient positioning of ducts may create unwanted microclimates, negatively affecting the thermal comfort of some occupants. In addition, despite following the ASHRAE Standard 55, due to the existence of individual difference in thermal preference (Wang Z. et al., 2018), conventional HVAC systems are likely to fail to deliver a comfortable range of temperature expectations for some occupants as any uniform environment likely cannot encompass the thermal needs of all individuals in the same space. With the advent of personal heating and cooling systems (devices that enable personal heating and cooling for each individual as seen in Figure 6) practitioners have new ways to accommodate for varying thermal preferences among building occupants that are not sufficiently resolved by HVAC systems alone (Zhang et al., 2015b).
With personalized heating and cooling devices, occupants are able to control their immediate environment and self-adjust to changes in their thermal preferences. Occupants have a greater degree of freedom in satisfying acute changes in their temperature preferences (Dounis and Caraiscos, 2009). However as with survey fatigue, manual adjustments of personal comfort systems over extended periods of time experiences a reduction in the device usage whereas operational autonomy of these devices can forego or eliminate these difficulties and therefore, have potential in becoming autonomous, responsive agents.

In summary, new approaches based on a personalized view of thermal comfort and rejecting uniform environmental control in favor of individual comfort are needed. Such a requirement can be addressed through the use of AI, a computer-controlled system capable of adapting to human learning processes and enacting actions justifiable by logical reasoning. Intelligent systems governed by AI should be able to function proactively without the need for intensive manual intervention to provide thermal comfort for building occupants while minimizing energy consumption. Implementation of such systems would lead to environments where occupants are either readily comfortable or can achieve comfort through very simple interaction points. Figure 7 depicts the higher level role AI-based building systems would play when connected and given access to the inflow of information from multiple operational technologies, which would allow for more accurate maintenance of occupant thermal comfort. Unlike the conventional legacy control theory (with a closed-loop feedback controller), the use of AI does not require a system model to operate efficiently (Ghahramani and Karvigh, 2017). Therefore, it offers greater potential for adapting to real world applications and monitoring occupant thermal comfort. In addition to the adaptability to the physical environment, AI can better accommodate the slight dynamic changes in occupants' thermal preferences by observing occupant behaviors overtime; a capability not matched by PMV and adaptive models. By using AI to regulate the communication and coordination of a structured set of operational devices controlling the thermal environment, we can address occupant thermal comfort more efficiently.

\section{ARTIFICIAL INTELLIGENCE FOR THERMAL COMFORT REQUIREMENTS}

One or an orchestration of intelligent entities (aka. rational agents) can be used to map the decisions made by AI to the physical environment. There are four descriptive aspects of a rational agent: (1) a performance measure, (2) the environment, (3) actuators, and (4) sensors (PEAS) (Russell et al., 1995). The performance measure is the criterion that measures the agent's success, the environment dictates the restrictive factors an agent may encounter in its operating space, and the actuators and the sensors work together continuously, as sensors process information and relay information to the actuator to carry out the physical changes in the environment. For example, in building environments, thermostats and HVAC systems are traditionally interlinked to accomplish the same goal. While thermostats only function to detect changes in temperature, 


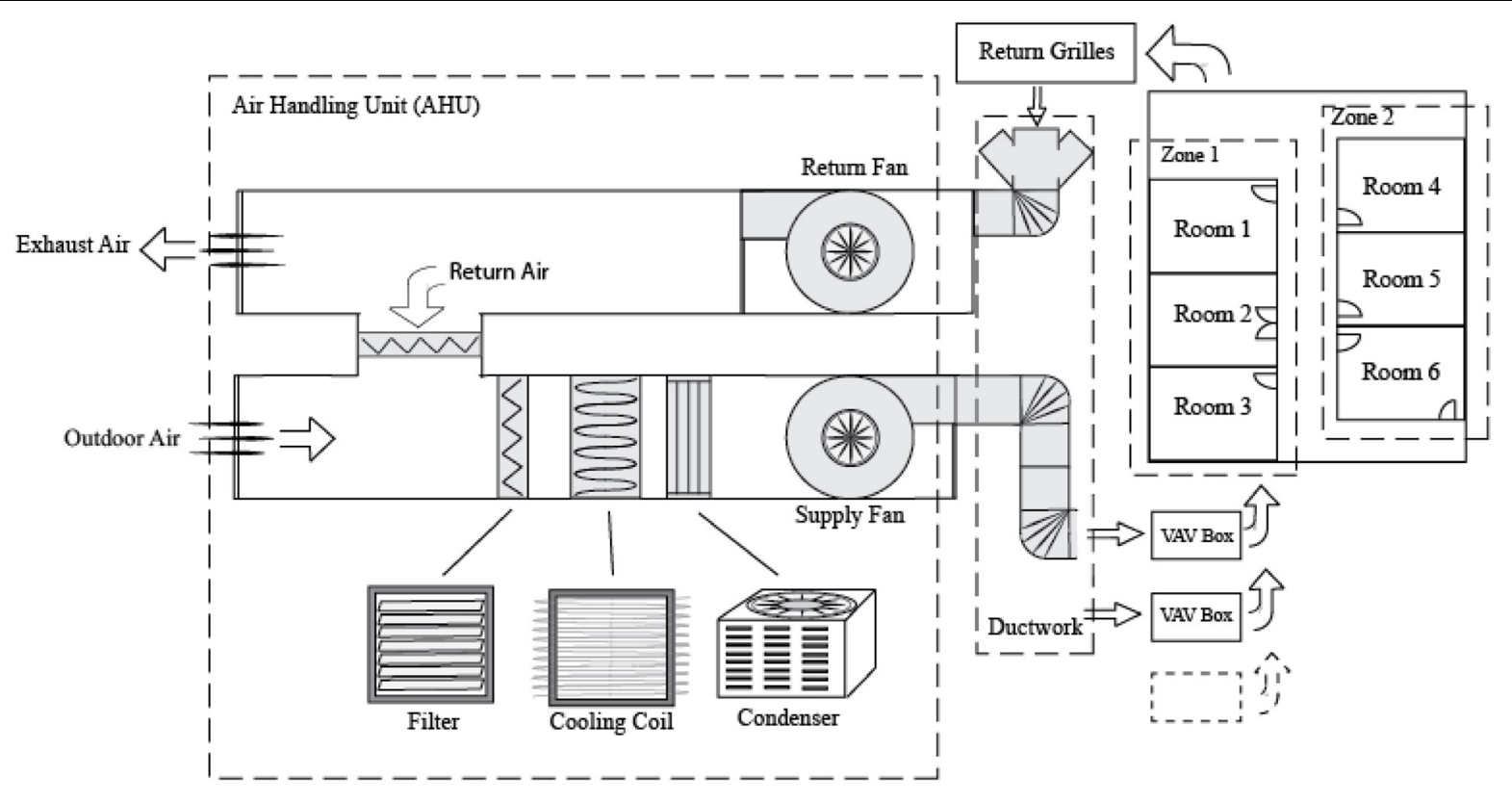

FIGURE 4 | Schema of a variable air volume air handling unit HVAC operational systems.

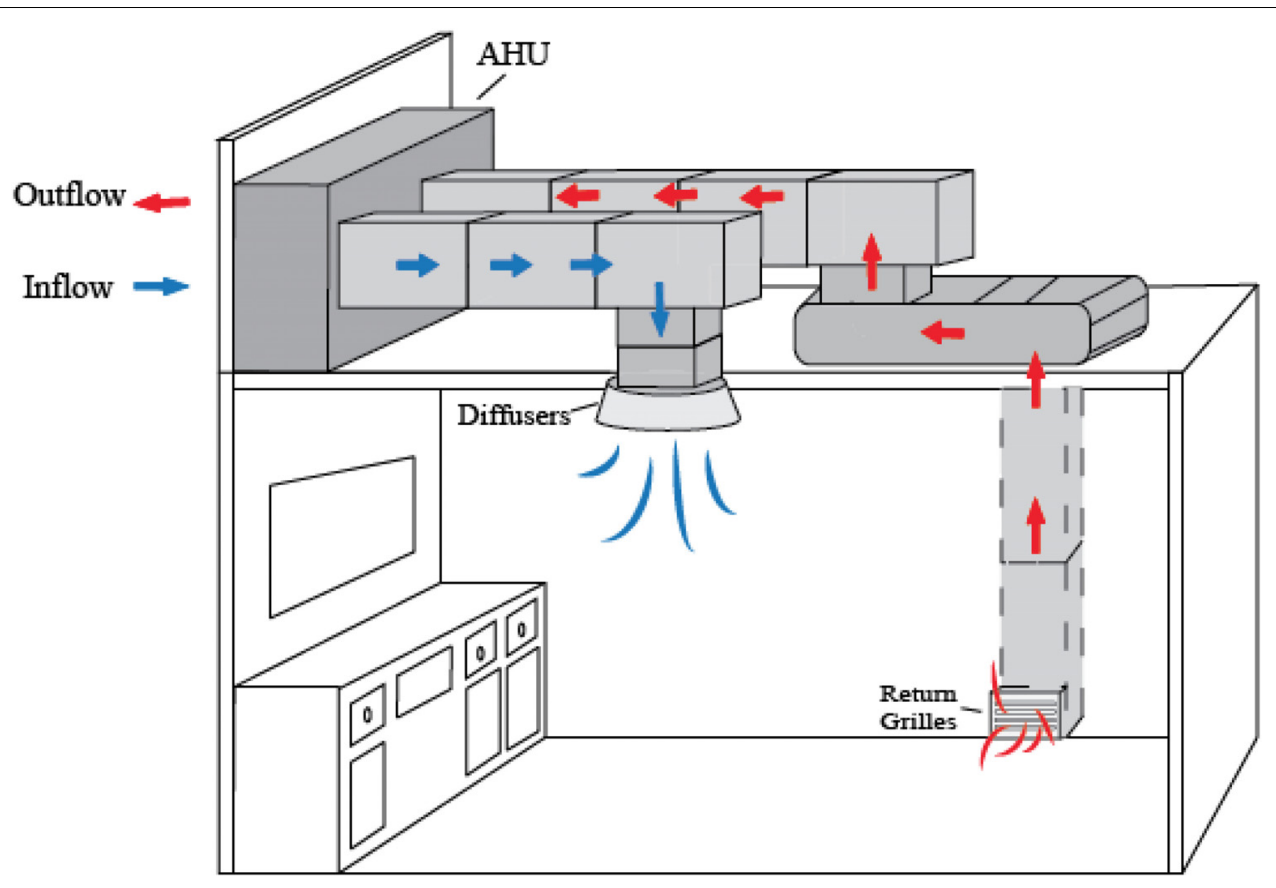

FIGURE 5 | Air circulation via HVAC systems as a means of proper ventilation of space.

HVAC systems primarily provide heating and cooling, but despite their different immediate primary functions, both are geared at maintaining comfortable indoor temperature. Rational agents are used to carry out the actions dictated by artificial intelligent systems, but to function effectively, components that control the agent's problem-solving process, the agent's rational decision-making capability, and the agent's ability to learn must all function correctly. In the field of computer science, these three components can be generalized by the following concepts: Search Algorithms, Logic Inference, and Machine Learning. For the purpose of understanding this paper, a brief explanation of only these three subsections of AI is explored. Each subsection is accompanied with implementation examples from the literature. 


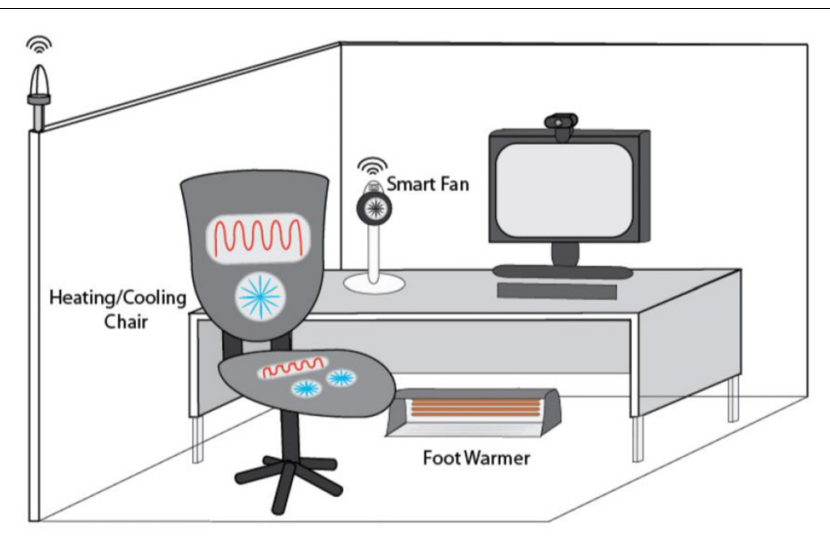

FIGURE 6 | Personal comfort systems (PCS) help resolve the unaddressed gaps of HVAC systems.

\section{Search Algorithms}

Artificial intelligent systems must be able to explore and pursue multiple routes to achieve a task, understand which routes yield better success rates, and narrow down the routes that lead to success most efficiently. When addressing problems with AI, prior knowledge of the correct sequence of steps required to reach the solution is often unknown so it must be explored using some version of the same trial-and-error approach (Korf, 2010). Such approaches vary based on four evaluations of the algorithm's performance: (1) completeness (i.e., can the algorithm guarantee a solution should one exist), (2) optimality (i.e., the ability of the search to find the most efficient route to the solution), (3) time complexity (i.e., time it takes to find and complete the task), and (4) space complexity (i.e., the amount of memory storage needed for the search) (Russell et al., 1995). Often the performance complexities (i.e., time and space) are the aspects that identify which search algorithm would best fit the problem space (i.e., the environment in which a search takes place; Newell and Simon, 1972). Some common types of search algorithms used are brute-force, hill climbing, simulated annealing, and heuristic algorithms (e.g., genetic algorithm), all of which are implemented at varying levels of difficulty. In building systems, search algorithms are used to explore the initial decision space, iterating through sequences of steps in building systems to determine certain combinations that deliver preferred results. For example, a search algorithm can determine the best operational time of HVAC systems in the morning to prepare a comfortable thermal environment for occupants as they begin a workday. The search determines the combination of setpoints that appeases occupant thermal comfort, which include the temperature of heating/cooling coils in the air handling unit (AHU) and the duration and intensity of airflow to quickly bring the room temperature to a comfortable state in the context of the outside environment, while consuming the least energy.

\section{Logic Inference}

The logic in AI is geared for creating rational thought and mapped to make rational decisions and achieve a goal. Typical basic machines can function similar to an $\mathrm{ON}-\mathrm{OFF}$ switch, taking binary inputs of 1 for true and 0 for false, but this configuration provides insufficient options to correctly model human logic and reasoning as our decisions do not necessarily always fall between a yes or no. More often than not, our decisions are based on partial information and can be designated between the range of right and wrong. Logic inference commonly refers to first order logic, which deals with objects and their relationships and expresses facts between objects. Building systems typically use logic inference in conjunction with search algorithms used to determine the decision environment. From the exploration of search algorithms in determining the best sequences to achieve a comfortable thermal environment with respect to outdoor conditions, logic can make the decisions for the system based on inferences on the relationship between the components found in the search (Han et al., 2011). Continuing with the previous example in Section "Logic Inference," while search determines feasible routes of success, logic inference determines the best option to take, specifying the exact temperature of the heating/cooling coils in the AHU, the exact time to initiate HVAC systems in the morning, the duration of time for its operation, and the intensity of airflow. Logic in systems improves inference rules as search algorithms gather information from the changing environment.

\section{Machine Learning}

Machine learning is a subset field of AI that primarily deals with programming computers to interpret complex data and evolve in performance with experience. In this paper, we focus on three main categories of machine learning: supervised learning (SL), reinforcement learning, and unsupervised learning (UL).

Supervised learning methods vary from interpreting and mapping linear relationships to non-linear relationships to address the different levels of complexities different problems. Algorithms used in SL often fall under two designations: (1) regression and (2) classification. Regression primarily assesses continuous numerical values that have some sense of codependence (e.g., cost-demand relationship), while classification problems aim to correctly predict discrete sets of information, often categorical (e.g., favorite colors). Perhaps the most basic type of SL algorithm is linear regression, a technique typically found in statistics, as this method assumes a linear relationship between an input and an output. Some common algorithms used in SL are decision trees, support vector machines, k-nearest neighbor, and artificial neural networks. These algorithms, because they differ in approaching the solution, have varying potentials for success with different problems. Sometimes the individual use of SL algorithms is insufficient in reaching a certain tolerance for a solution to problems, so a technique called ensemble learning is implemented. Ensemble learning involves the collective use of multiple SL methods, working together to reduce variance and improve accuracy of an automated decision-making system (Quinlan, 1996). A common example for ensemble learning is called the random forest, a method that uses a collection 


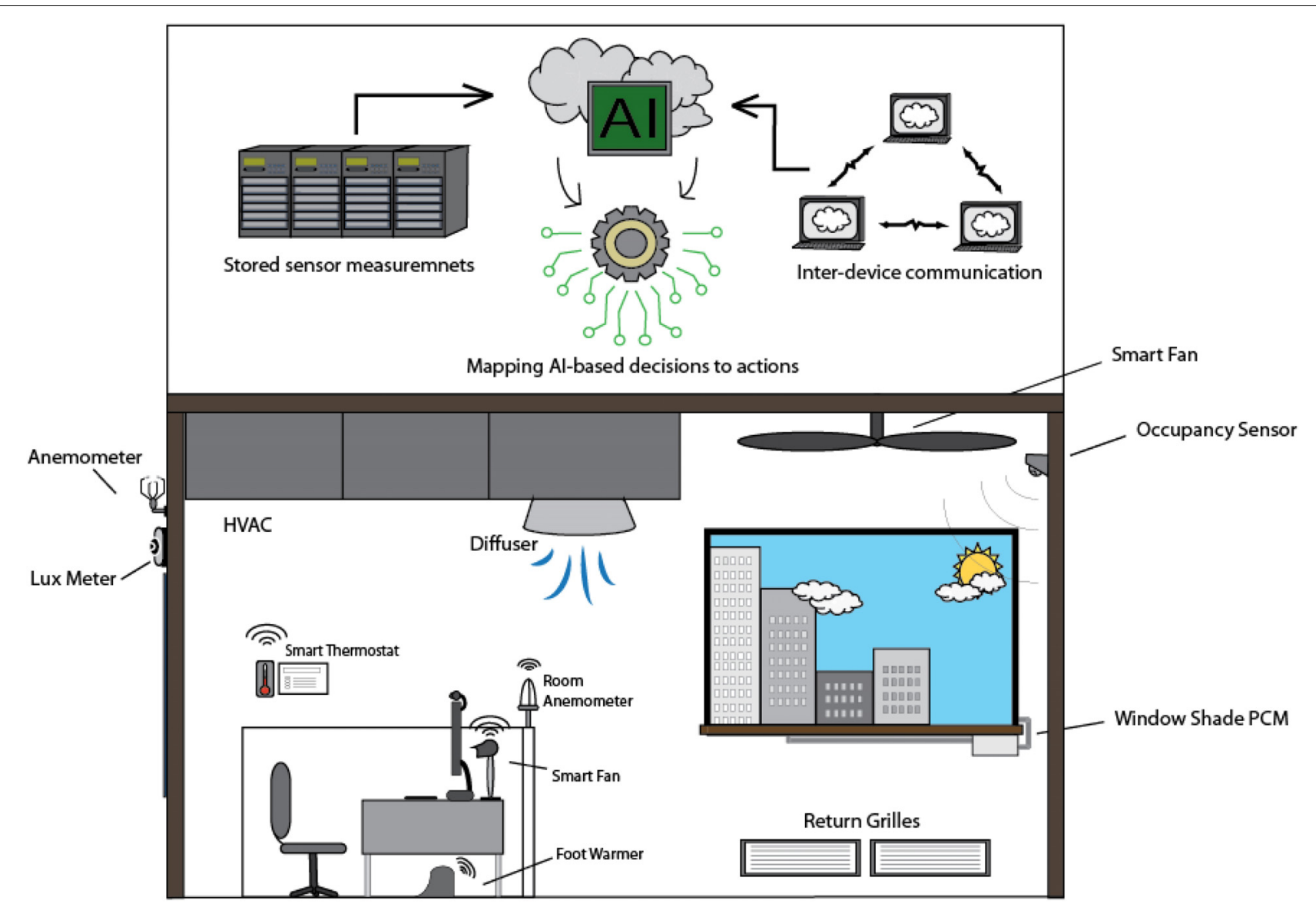

FIGURE 7 | Sensors are connected to the building automation system and relay real-time sensor measurements that allow for optimal performance of the Al-based system.

of decision trees working cohesively. Although the typical uses for these algorithms vary, they can all be susceptible to overfitting, a problem referring to a model that matches a data set too closely that generalization of the data becomes difficult. With the aid of temperature sensors indoors and outdoors, SL algorithms are able to map the relationship between the outside temperature to the correct indoor temperature that would provide occupant thermal comfort (Jazizadeh et al., 2013, 2014). For example, by training the algorithm to recognize typical temperature ranges for different seasons, the algorithm can classify the outdoor temperature reading to a certain season. Based on the context provided by the season, the algorithm can map the outside temperature to the closest expected indoor temperature that provides thermal comfort (perhaps by using K-nearest neighbor) and, by taking the indoor temperature reading as reference, HVAC setpoints can be adjusted to satisfy the difference in temperature between the current indoor temperature and the expected (mapped) indoor temperature. The implementation of these algorithms in the context of achieving maximum occupant thermal comfort can help determine the relationship between input-output pairs to allow building systems to adjust and reach a comfortable thermal environment (Zhao et al., 2014; Ghahramani and Tang, 2015; Ghahramani et al., 2016a; Lee et al., 2017; Kim et al., 2018; Zhang et al., 2018). Other more specialized SL techniques such as computer vision-based techniques uses a visible-light (Jazizadeh and Pradeep, 2016) or infrared images (Cosma and Simha, 2019; Li et al., 2019) to extract physiological features which are then used to developed personal comfort prediction tools.

Reinforcement learning studies the relationship between the learning agent, the environment in which it operates, and the reward value gained from the agent's interaction with its environment. This learning type involves the ability of an agent to discover the best chain of actions to reach a solution that also yields the most reward (Sutton et al., 1998). Unlike SL, reinforcement learners are not pre-equipped with knowledge from training examples. Instead, reinforcement learning is more focused on learning from interacting with the problem space and assigning each action to a numerical value, where higher values suggest the learner made better decisions to reach an end goal. A unique challenge facing reinforcement learning is the trade-off between the costs of the exploration and the additional learned knowledge of the exploration (Sutton 
et al., 1998). A learning agent's goal is to discover the best actions that lead to the most reward, so it must be able to exploit the knowledge it has from previous actions and decide newer avenues to explore for the possibility of receiving greater rewards. A commonly used technique of reinforcement learning is Q-learning because it does not need a model of the environment, which makes it adaptable and versatile to broad types of problems. Reinforcement learning can help model the thermal environment in which tools regulating thermal comfort, whether spanning the building (i.e., HVAC systems) or an individual occupant (i.e., personal comfort systems; Zhang et al., 2015b), operate (Dalamagkidis et al., 2007). Take the relationship between a thermostat and a manually controlled HVAC system as an extended example from Section "Logic Inference." Using the temperature fluctuations at the beginning and during the workday sensed by temperature sensors, reinforcement learning algorithms can be trained to recognize the pattern in temperature changes with respect to time. Under the assumption that the mean temperatures observed during a period of time reflect the comfortable thermal environment occupants prefer, reinforcement learning algorithms can automate the adjustments in HVAC system setpoints to deliver the observed temperatures at given times of the day. As occupants continuously change temperature setpoints via a thermostat, the reinforcement learning algorithm can adjust accordingly and converge on a path that optimizes time and rewards gained in the problem space; hence, the most accurate control of HVAC setpoints that maintains occupant thermal comfort (Chen et al., 2018).

Unsupervised learning is often implemented in problems where prediction labels (i.e., the characterization of corresponding outputs from given inputs) are not available, making UL more readily applicable to real-world problems. The central task of UL algorithms is to cluster datasets based on a measure of similarity dictated by different algorithms. A common class of UL algorithms is clustering. Some examples include K-means clustering, hierarchical clustering, and spectral clustering. These UL methods are useful in their ability to find inter-relationships between complex real-world data without any given prediction labels. Hence, they are more adaptable to complex, reallife applications. With UL techniques, the adaptability of current air conditioning systems can be improved to manage drastic or unexpected changes in the environment (Ghahramani et al., 2018). In buildings, HVAC systems may operate uniformly across the building space, delivering the same temperature and airflow volume for each zone (i.e., a common lounge area is at the same temperature as each individual office room in the building). However, with the use of UL algorithms, aided by temperature sensor inputs, different zones of the building can be adjusted to be slightly cooler or hotter relative to other zones based on the occupant preferences in those zones. UL algorithms can categorize zones with similar temperature variations under the same HVAC setpoints such heating or cooling changes in both rooms happen in parallel (Xiao and Fan, 2014; Miller et al., 2018).

\section{CURRENT APPLICATIONS AND REQUIREMENTS OF ARTIFICIAL INTELLIGENCE FOR THERMAL COMFORT IN BUILDINGS}

In this chapter, we discuss the current applications of devices from two categories of systems (disjoined and connected systems) which differ due to the extent of integration and control of AI in the intelligent system. We specifically focused on the efforts published in the literature on the usage of intelligent of systems for personalized thermal comfort.

\section{Disjointed Systems}

We categorize disjointed systems as those lacking technological connectivity, and using operational devices that lack central monitoring and inter-device communication to regulate occupant thermal comfort. Therefore, we describe smart systems (connected and programmable systems which might have AI components) which operate in isolation for providing personalized comfort: (1) smart thermostats (Pienta et al., 2014) that have the capacity to store, in its memory, a set of actions that it can automatically enact based on changes in the thermal environment. Using the detected room temperature as well as the user programmed temperature threshold, the smart thermostat is able to analyze both measurements and determine an operation state to adjust to the environment system, all without user intervention. In doing so, the thermostat signals the HVAC system to adjust accordingly and provides an audible notification to the user, alerting of the adjustments made. Unlike thermostats that cater to an entire space, devices such as smart blankets and fans specifically cater to the needs of its user. (2) Intelligent fans allow users to configure certain indoor temperature setpoints to allow the automatic operation of electric fans in the context of the outdoor temperatures when an occupant is present in the space. (3) Intelligent blankets (Yang et al., 2009) are more often found in medical contexts as they aid in proper regulation of a patient's body temperature. Using interlinked wires in the blanket for heating, the user is able to dictate the target core temperature of the patient. The warmth offered by the blanket adjusts accordingly to reach the goal body temperature of the patient based on the user-determined setpoint and maintain it. (4) Using flexible conductive materials and integrating a carbon conductive woven fabric as the heating element, the regulation of the user's thermal comfort becomes more feasible as the resistivity of the carbon fabric is reactive to temperature changes; this material effectively provides more heating as the temperature decreases (Rantanen et al., 2000). As with the intelligent blankets, an obvious drawback includes the inability of both devices to effectively reverse the heating process and cool the user. (5) Phase change materials (PCM), substances that melt or solidify in response to exposure to different temperatures, acting as latent heat storage (LHS) units, capable of releasing or absorbing heat. Smart windows made of PCM, for example, help regulate indoor temperature. One experiment with PCM specifies the use of a PCM moving curtain (Ismail and Henriquez, 2001) 
that includes two glass panes enclosing a small gap of air. This technology uses thermocouples to measure the temperature of each glass pane and once a pre-determined difference is detected, a small pump will enable the flow of a PCM liquid in the space, which solidifies overtime and therefore reducing the amount of sunlight penetrating through the space, hence controlling the exposure of the occupied space from high ambient heating (Pasupathy et al., 2008). Current operational devices used in disjointed systems are capable of responsive actuation (based on sensor measurements) making them fast response and resilient to network disruptions and cyber-attacks, therefore having lower chances of service failure. However, they have better potential in becoming more responsive to a wider array of scenarios (including unexpected thermal conditions) in the building environment and more receptive/adaptive to the slight variations in occupant thermal preferences under the control higher level artificial intelligent systems.

\section{Connected Systems}

We define connected systems are those with centralized monitoring systems linking all operational devices. However, the key characteristic of truly connected systems would be capability of enacting complex control algorithms to remotely govern the performance of each device connected to the system. With greater connectivity, the performance of each device will better contribute to the system providing a comfortable environment; with sensor integrations, the intelligent system's fault-detection capabilities will be improved to retain a consistently comfortable thermal environment. Using sensor data, the AI elevates our control of the building environment by making orchestrated changes in the functions of all connected devices to account for the changes in the thermal environment. This intrinsic level of connectivity may capture health, well-being, and thermal comfort benefits without heavy energy expenditures. Unlike disjointed buildings, the technology in connected buildings will require integration through the Internet of Things (IOT), characterized as a network of internet-connected technological devices capable of exchanging data that inevitably increases their collective performance efficiency with limited human intervention. With IOT, operational devices in connected buildings are more compatible to the implementation of $\mathrm{AI}$, which functions as the central brain of the operation, using shared data from all connected devices to enact real-time, refined changes to the thermal environment (Marche et al., 2017). Using the inflow of information for observation, learning algorithms are continuously improving in modeling the environment and in finding more accurate relationships between the variables in the occupied space (Ray, 2016). In turn, the logic rules used by the AI also adjust to become more refined, optimizing the correct decisions made by the intelligent system. Sensor measurements from the thermocouples in smart window panes may communicate with PCSs, such as seat heating pads or foot warmers, or with the HVAC system when a light intensity threshold has been reached and the PCM will slowly block the penetrating sunlight and hence restrict the source of ambient heating. By the thermocouples signaling this change in the thermal environment, PCSs or HVAC systems can activate and gradually provide heating to compensate for the same ambient heating provided by sunlight to maintain a comfortably balanced thermal environment. With streamlined access to the performance of each individual device in operation provided by IOT connections, a smart system can directly make changes to single devices or make an orchestrated change, altering multiple devices accordingly such that the thermal environment of the entire building lies within a comfortable range. With this ability, smart buildings have the greatest potential in adapting to and addressing a broader set of conditions.

The implementation of AI in building management systems (BMS) having linked various operational devices in a building for smart monitoring (Roth et al., 2002) may create a connected system as the AI uses sensor measurements in assessing the performance of each device and finding the optimal usage configuration of all devices to improve energy efficiency in delivering a comfortable thermal environment. Ambient sensors (e.g., temperature, relative humidity, and air pressure/speed) directly connected to the BMS provide the information pertinent to thermal comfort that the AI will monitor and use in its assessment of further actions to be taken (Doukas et al., 2007). However, for the best performance of BMS-controlled HVAC systems, the decisionmaking AI must actively find the optimal balance between the occupant preferences as well as the energy performance of the building system (Dounis, 2010). There are many ways in which an intelligent system can make useful logical decisions that correctly address occupant comfort. Intelligent systems have been implemented and trained with various techniques. For example, artificial neural networks have been used to optimize the start times of HVAC systems (Yang et al., 2003) to match occupant use patterns. Other approaches include genetic algorithms to optimize the occupant thermal preferences with respect to minimizing energy consumption (Kolokotsa et al., 2002). The values outputted by the genetic algorithm are used by the HVAC controllers as the new setpoints to better regulate the occupant thermal comfort (Dounis and Caraiscos, 2009). Aside from the use of ANN and genetic algorithms, some BMSs implement a reinforcement learning technique to increase the adaptability of the HVAC controller with different environments (as discussed in the extended example from section "Logic Inference"). Since reinforcement learning does not require input from an external knowledgeable source to learn, the system can adapt to unexpected building conditions (e.g., leaks) (Dounis, 2010). Despite the promising results from the use of machine learning techniques to optimize HVAC setpoints, allowing external intervention into the operation parameters of these techniques can further improve system efficiency and speed. For example, smart selection of higher setpoints in the summer and lower setpoints in the winter would deliver appropriate thermal comfort while conserving energy as research shows that occupants have preference for higher and lower setpoints for summer and winter seasons, respectively (Jendritzky and de Dear, 2009). 

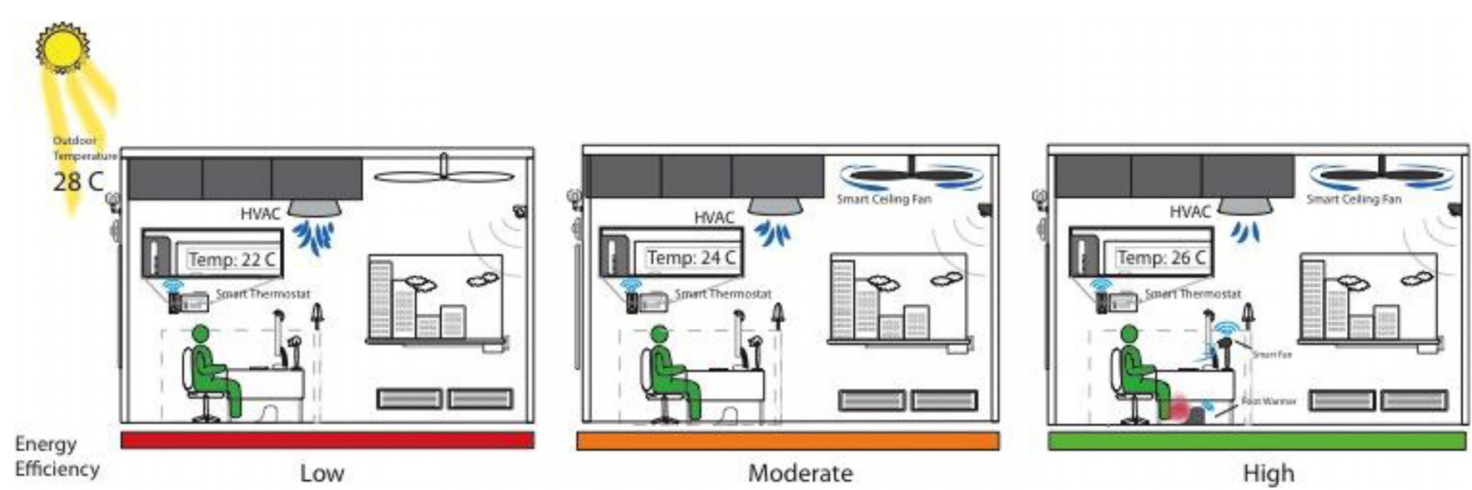

FIGURE 8|A progression of improving energy efficiency in providing occupant thermal comfort by optimizing the orchestrated use of the HVAC system and PCSs in the occupied space.

\section{FUTURE DIRECTIONS FOR ENABLING AUTONOMOUS PERSONALIZED THERMAL COMFORT SYSTEMS}

Often the devices we categorized for disjointed systems need further improvement to meet the requirements we have imposed to achieve compatibility with AI in connected systems. Additional devices that must be integrated into the simpler technology used in disjointed systems are IOT enabling components (e.g., wired or wireless communications) or extra sensing modules (Agarwal and Weng, 2012). This enables users to personally interact with operational devices individually (Kolokotsa et al., 2011). Sensors currently on the market can be used to aid in the performance monitoring of the devices found in disjointed systems, but the user would have to install them as devices already fitted with specific sensors are not common. For example, windows and window shades can be used to improve thermal comfort in buildings, allowing users to manually restrict the airflow as well as sunlight (i.e., a source of ambient heating) that penetrate the space by modifying the openings of the window and the window shades (Kates, 2008). Using actuators, the physical movement of windows and window shades can be mechanized, and, with sensors, the movement of both can become responsive (automated). By outfitting mechanized windows and window shades with anemometers and light meters, respectively, the system would be able to detect changes in the airflow and intensity of sunlight and automatically adjust the operation of windows and shades to preserve a comfortable thermal environment. Duct anemometers can also be installed in the ducts of the HVAC system that can notify the user of the airflow movement within certain ducts (Ghahramani et al., 2019b). This will help users deduce whether retrofits are needed and more accurately dictate the setpoints for the HVAC system. Electric fans can also be outfitted with occupancy sensors as well as temperature sensors to operate automatically when occupants are present and respond to environmental conditions to improve both thermal comfort and air freshness in the breathing zone (Ghahramani et al., 2019a). IoT-based (e.g., WiFi network) occupancy detection and tracking systems can also be leveraged to accommodate the occupants movements indoors (Rafsanjani and Ghahramani, 2019, 2020). Similar to the windows and window shades, the functionality of electric fans can be further improved by connecting to outdoor anemometer sensors or light meters as information from both sensors can help the intelligent fan deduce the intensity and duration of its operation to maintain a comfortable thermal environment (Tsuzuki et al., 1999). When the air movement goes below the allotted tolerance for the anemometer, the fan can turn on and make up for the lack of natural air movement with circulation of the air in the space. If the light meter measures a luminance higher than the provided tolerance, it can close the window shades as well as turn on the fan (Soori and Vishwas, 2013). However, this relationship hinges on the premise that increased sunlight suggests high temperatures outside, which is not always correct and would be dependent on geographic location. The integration of the dynamic field of AI suggests further improvements in the potential of AIcontrolled intelligent systems for building automation. As the field of AI and the use of smart operational technologies grows, we expect more refined and more responsive intelligent systems in the built environment; capable of adapting to a broader set of circumstances in the thermal environment as well as variable shifts in occupant thermal comfort preferences overtime. Figure 8 shows an example of energy use through a progression optimizing the collective performance of operational devices to deliver a comfortable thermal environment for building occupants. As it can be seen in the figure, the low energy efficiency case would only use the smart thermostats and other comfort sensing technologies to select optimal setpoints at the zone level through central HVAC system for conditioning the space. In the moderate efficiency case, in addition to central HVAC system, the ceiling fan serving the whole room would help in providing comfort. In the high efficiency case, the personal comfort systems would help HVAC system and ceiling fan to provide comfort and thus reducing overall energy consumption (up to $32 \%$ and vary depending on the building characteristics; Ghahramani et al., 2016b). While the savings highly depend on the building type and usage, climate and system optimization method, developing a simulator framework for estimating energy savings 
achievable through different levels of efficiency criteria would quantify the trade-off between efficiency, cost, and comfort. This could be pursued as crucial research direction in personalized conditioning of spaces.

Next, we describe components required for delivering this objective.

\section{Improving Thermal Comfort Sensing and Learning Techniques}

The success of BMS-operated buildings is contingent on the ability to learn from occupants of the space (Ghahramani and Jazizadeh, 2014). To achieve a higher degree of symbiotic relationship between operational devices and building occupants, further studies in thermal comfort learning techniques are needed. The AI in BMS or BMS-operated buildings is, in simplest terms, a collection of programmable rules that guide the learning and decision processes of the machine (Rafsanjani et al., 2015), which makes their efficiency dependent on its ability to learn from occupant behaviors (Ghahramani et al., 2015b). One way to improve the functionality of the intelligent system will be to improve the standards by which we identify and categorize the thermal comfort preferences of each individual in the occupied space. To accomplish the complex task of retrieving the dynamics that constitute for occupant thermal preferences, we should forego inefficient and inconvenient survey-based learning models and instead pursue more adaptive methods which keep track of personal comfort over time (Ghahramani and Tang, 2015). One non-intrusive learning technique focuses on physiological measurements via stationary sensors in the environment (e.g., heart rate, respiration, blood perfusion, skin temperature measurements; Huizenga et al., 2004; Takada et al., 2013; Liu et al., 2014; Ranjan and Scott, 2016; Song et al., 2016) as a predictive approach in determining the occupant thermal comfort. Showing a correlation between facial temperature measurements and occupant thermal comfort using infrared thermography (Ghahramani et al., 2016a, 2018; Ranjan and Scott, 2016) will be a step toward further non-invasive learning techniques for predicting the dynamics of thermal comfort, which can contribute to a more convenient data collection methodology for personal thermal comfort profiles. The key premise of this approach hinges on the sensitivity of the human head and face to the thermal environment due to large concentration of arteries needed for thermoregulation purposes. Other non-intrusive methods to gather data and build occupant thermal comfort levels include wearable sensing devices. Wearable technology would also allow unprecedented access to the study of human behavior and hence, generate accurate data that can be used to provide the most suitable thermal environment for the user of the wearable device in the occupied space. Skin temperature, heart rate, and sweat measurements have already been investigated for estimating personal thermal comfort (Li et al., 2017). However, further developments are needed for the use of wearable technology to be feasible. For example, along with being non-intrusive, such devices must be able to record and store data for a prolonged period of time, to relay the information via a wireless network, and to provide some practical value for the user. Whether a ring that measures heart rate, a bracelet that detects perspiration, or a watch that estimates core body temperature, wearable technology has a potential future along with automated buildings (Figure 9). Having comfortable and non-invasive wearable devices, gathering data may become easier and more dynamic as sensors would be able to detect changes in the user's bodily functions in the context of multiple thermal environments.

\section{Personal Thermal Comfort Profiles}

To deliver such an unprecedented level of attention to the dynamics of individual occupant preferences, a method to generate accurate and dynamic thermal comfort profiles of all occupants must be developed (Ghahramani and Tang, 2015). Such thermal comfort profiles would outline a history of occupant thermal preferences in the context of a variety of thermal environments, so the AI in building systems can better discern the thermal comfort needs of each occupant. One apparent benefit of personal thermal comfort profiles will be in our ability to create a more hybridized approach in delivering occupant thermal comfort by physically isolating occupants into specified building zones using their personal comfort profiles such that intelligent devices can better regulate thermal comfort uniformly (Murakami et al., 2007; Yang and Wang, 2013; Zhang et al., 2015b). Such a scenario was explored where occupant profiles were generated using modeling techniques, one of which include pattern recognition modeling (neural network algorithm), taking into account the ambient context (i.e., $\mathrm{CO}_{2}$ concentration, door status, light level, binary motion, and temperature) of the zone under study. Once occupant profiles have been generated for the different zones in an occupied space, clustering algorithm (e.g., K-means clustering) can be implemented to identify the groups of occupants with the closest degrees of similarity. After which, human intervention is encouraged to physically isolate building occupants into

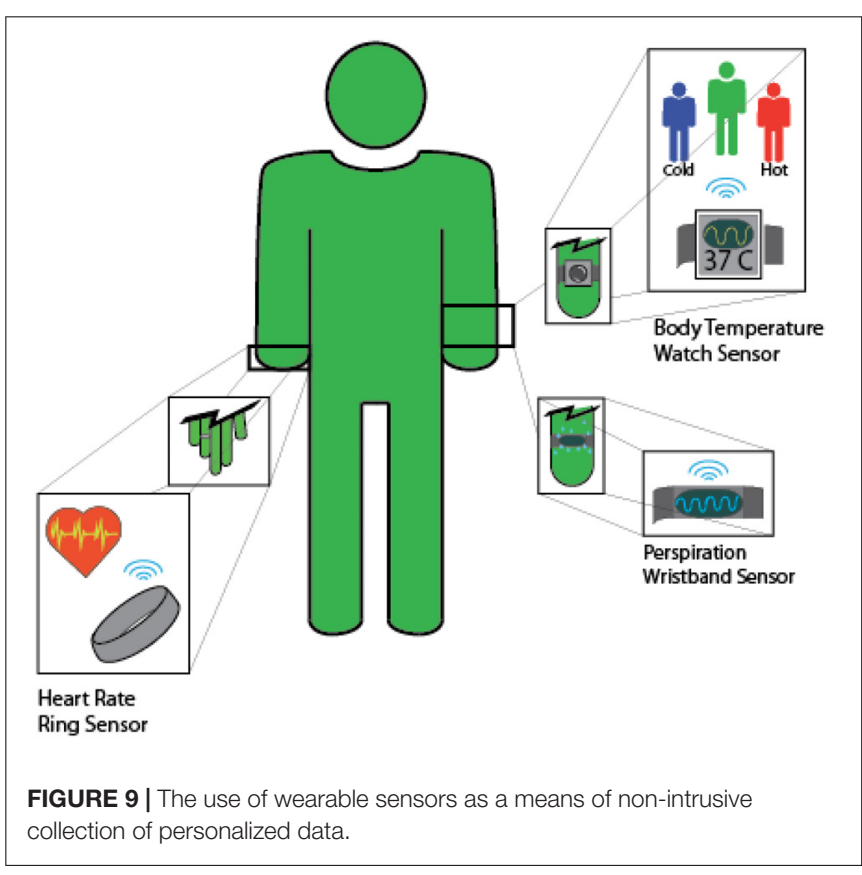


respective zones such that thermal comfort regulation for an entire zone better caters to the slight differences in thermal preferences of the collective group. Although the merit of a hybridized approach is understandable and may cater to a greater percentage of occupants' thermal preferences, it may take more effort and time to achieve. With personal thermal comfort profiles, the AI in BMSs can better control the thermal environment around the individual in accordance to their thermal comfort preferences. For example, using the raw data from the wearable sensors outlined in Figure 9 or from infrared thermography, an intelligent system can use deduce the overheating threshold of the individual and prevent this scenario from repeating in indoor environments. With access to personal thermal comfort profiles, a BMS serving spaces that have routine occupancies, such as offices, can take advantage of similar thermal comfort profiles by isolating different workers into zones based on a certain degree of similarity of their thermal comfort profiles (Murakami et al., 2007). In doing so, the HVAC system can be more efficient in catering to the similar needs of occupants, as opposed to addressing thermal comfort levels of occupants with great variations in thermal preferences. However, to develop more accurate, self-updating thermal comfort profiles, newer non-invasive techniques that limit human intervention and contribute to a more autonomous building system must also develop concurrently.

\section{Personal Comfort Systems and Usage Habits}

Although a building automation system would be capable of analyzing data from wearable sensors, it would also need an extended network of operational devices (Figure 6) (Rafsanjani and Ahn, 2016) in the occupied space to provide the space conditioning needs of occupants based on their profiles (Luo et al., 2018). For an automated building to create individual microclimates around the occupants based on their thermal profiles will require personal comfort systems. To generate such a microclimate, personal comfort systems must be available to all individuals in an occupied space. Personal comfort systems come in many different forms to address slight changes in thermal comfort needs of each individual, so it would be necessary to have a collection of these devices dedicated for the occupant in the immediate space (De Dear et al., 2013; Pasut et al., 2013; Zhang et al., 2015b). For example, if one person's thermal comfort profile suggests high sensitivity to slight drops in temperature, the BMS can activate the foot warmers located beneath the desk to provide consistent heating. Similarly, should the intelligent system recognize that an occupant has naturally high body temperatures, it can initiate fans that can direct airflow toward the occupant's head (as research reveals the high sensitivity of thermoreceptors in the human face would disseminate a cooler thermal feeling throughout the body; Luo et al., 2019). The collective use of personal comfort systems to address the thermal comfort will also be more efficient as opposed to using traditional HVAC systems with predetermined setpoints that provide blanket regulation of entire zones, not fully addressing individual differences in thermal preferences (Pasut et al., 2015; Zhang et al., 2015a; Luo et al., 2018). Allowing data from these personal thermal comfort profiles to be transferrable to other BMS-operated buildings will also expand the capacity of the built environment to ensure occupant thermal comfort by eliminating the dependence of thermal comfort

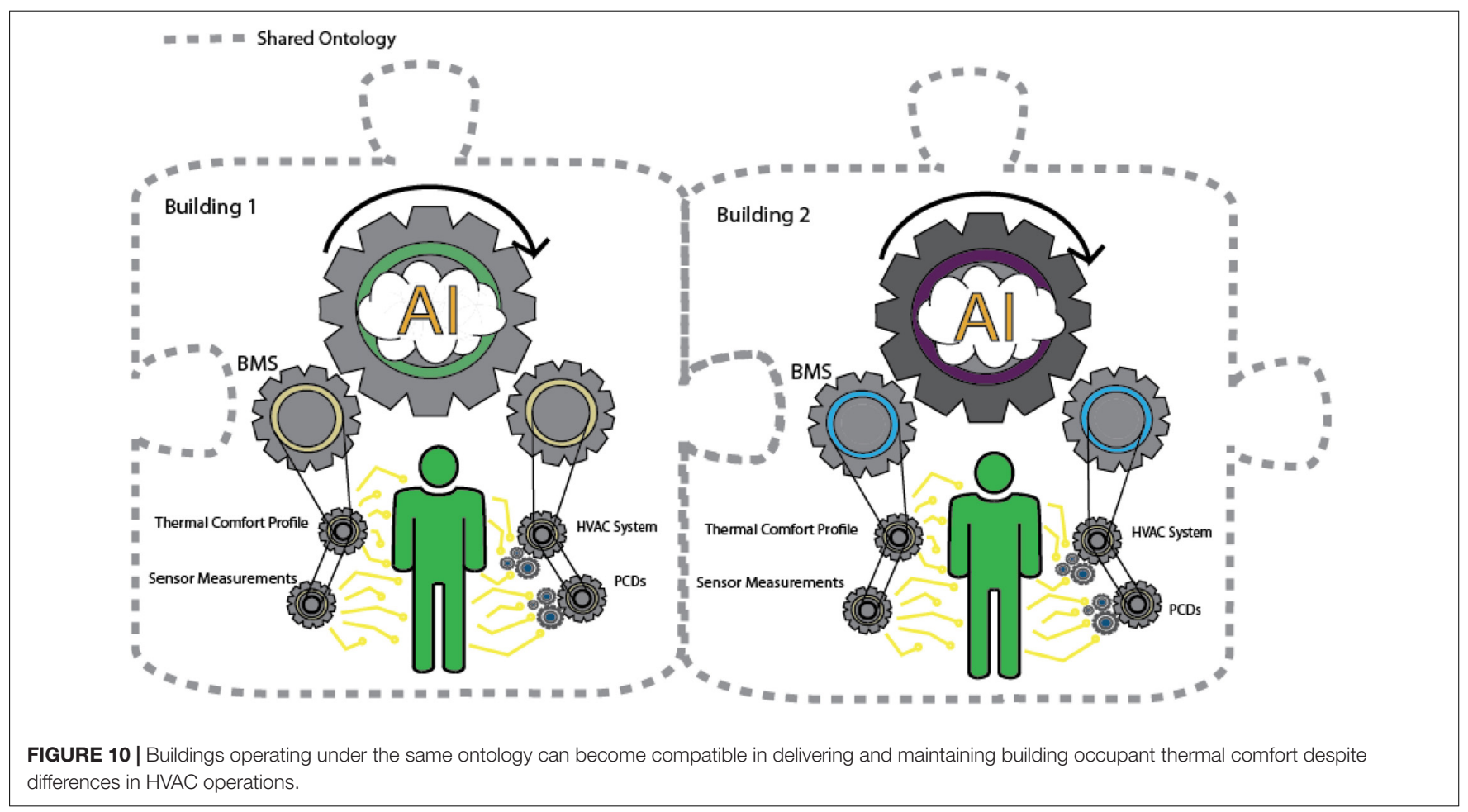


regulation on the available operational devices in the occupied space. Also, instead of learning occupant behavior only from times in which the individual is present in the room, raw data from personal thermal comfort profiles can allow the BMS access to a history of behavior and physiological responses of the occupants to changes in the thermal environment. With future developments in automated buildings, it is feasible to expect a wider distribution of operational devices regulating occupant thermal comfort in all occupied spaces within the built environment. As the future of automated buildings approaches a more coordinated relationship between human behavior and proactive machine responsiveness, we suggest that intelligent systems should become more standardized to ease the difficulties in an increasingly more complex network of remote-controlled operational devices.

\section{Development of BMS Using Ontologies}

The building industry suffers from problems with BMS interoperability as manufacturers use differing specifications and naming conventions on elements and functions. We see a need for study of the integration of BMSs using ontologies to advance the cross-operational potential of BMS. Ontology can be defined as a shared domain understanding that can be communicated between people and heterogenous and distributed systems (Russell et al., 1995). In other words, establishing an ontology for the operation of BMS can assist in creating a standard for the representation, designation, and definition of the objects and their properties in use. Creating this shared domain of understanding among various BMS allows for vendor-independent compliance (Charatsis et al., 2005) (i.e., interoperability), which can bring consistency in operation among all systems despite the variability in their design. Through the implementation of ontology, the operation of building systems can be generalized to a higher level, abstract model (Brizzi et al., 2016). Figure 10 shows a high-level conceptual depiction of the possible interoperability among different buildings that share the same ontology. Because of the hierarchy behind the abstract schema, changes by AI on the abstract model can simply be disseminated to various connected systems and translated using the respective operational conventions of each building system (Corry et al., 2015). The use of ontologies may eliminate the difficulties restricting smooth interoperability between BMSs. The common language/database offered by the creation of an open-source ontology can also make the use of personal thermal comfort profiles feasible with a greater variety of systems in the built environment. This will help eliminate possible incompatibility between occupant profiles and the capability of the HVAC system to execute the necessary adjustments to provide a comfortable thermal environment for the occupant. As technological developments help close the gap in the variations of HVAC functions, personal comfort profiles will become more compatible for use to a wider variety of buildings and hence, occupant thermal comfort levels will be upheld more regularly indoors.

\section{CONCLUSION}

To capture personal thermal comfort in a non-intrusive manner and provide comfort to all building occupants, it is necessary to have an integrated system of sensors (e.g., wearable sensors/infrared sensors), infrastructure for enabling system interoperability, learning and controls algorithms, and actuators (e.g., HVAC system setpoints, ceiling fans, personal comfort devices) to work under a governing central intelligent system.

To enable the improvements in both comfort and energy efficiency, in this paper, we discussed the data and system requirements for enabling intelligent system operations by describing fundamentals of an intelligent entity (rational agent) and components of its problem-solving process (i.e., search algorithms, logic inference, and machine learning). We then discussed the current application of intelligent personal thermal comfort systems in buildings by describing comfort related disjointed and connected systems. We finally describe future directions for enabling application of fully automated systems to provide personal comfort in an efficient manner. Moving forward, improvements in intelligent system methods will be needed to autonomously address the dynamic personal thermal comfort preferences of occupants in buildings. More complex control algorithms should be implemented in the BMSs, so the intelligent system is better equipped to manage the equally complex data inputs from all personal thermal comfort profiles in the occupied space and deliver a suitable thermal environment. With more operational devices connected to a BMS, the intelligent system controlling the function of personal comfort systems could ascertain the correct combination of devices to activate and for how long in order to increase the overall efficiency of the system.

\section{AUTHOR CONTRIBUTIONS}

AG was the lead author and the main content developer. PG was the primary literature investigator and the developer of the graphical contents. DL was the main manuscript editor and provided directional comments. ZV was the lead industry expert on guiding the literature search and structuring the manuscript. ZW contributed to the review to ensure its completeness and scientific contributions. YP was the main industry expert that provided advice on how to develop the review.

\section{FUNDING}

This material is based upon work supported by the Ingersoll rand Inc. There was no specific award number for this industry/academic effort.

\section{ACKNOWLEDGMENTS}

Special thanks to all the participants and specifically to Prof. Ed Arens for his contributions in guiding the research project. 


\section{REFERENCES}

Agarwal, Y., and Weng, T. (2012). From buildings to smart buildings-sensing and actuation to improve energy efficiency. IEEE Design Test Comput. 29, 36-44. doi: $10.1109 / \mathrm{mdt} .2012 .2211855$

Arif, M., Katafygiotou, M., Mazroei, A., Kaushik, A., and Elsarrag, E. (2016). Impact of indoor environmental quality on occupant well-being and comfort: a review of the literature. Intern. J. Sustain. Built Environ. 5, 1-11. doi: 10.1016/j.ijsbe. 2016.03.006

ASHRAE Standard 62-2001 (2010). Ventilation for Acceptable Indoor Air Quality. Atlanta, GA: Refrigerating and Air-Conditioning Engineers Inc.

Bedford, T., and Warner, C. (1939). Subjective impressions of freshness in relation to environmental conditions. Epidemiol. Infect. 39, 498-511. doi: 10.1017/ s0022172400012146

Brager, G. S., and de Dear, R. J. (1998). Thermal adaptation in the built environment: a literature review. Energy Build. 27, 83-96. doi: 10.1016/s03787788(97)00053-4

Brizzi, P., Bonino, D., Musetti, A., Krylovskiy, A., Patti, E., and Axling, M. (2016). "Towards an ontology driven approach for systems interoperability and energy management in the smart city," in Proceedings of 2016 International Multidisciplinary Conference on Computer and Energy Science (SpliTech), Split.

Charatsis, K., Kalogeras, A., Georgoudakis, M., Gialelis, J., and Papadopoulos, G. (2005). Home/building automation environment architecture enabling interoperability. Flexibil. Reusabil. 4, 1441-1446.

Chen, Y., Norford, L. K., Samuelson, H. W., and Malkawi, A. (2018). Optimal control of HVAC and window systems for natural ventilation through reinforcement learning. Energy Build. 169, 195-205. doi: 10.1016/j.enbuild. 2018.03.051

Corry, E., Pauwels, P., Hu, S., Keane, M., and O’Donnell, J. (2015). A performance assessment ontology for the environmental and energy management of buildings. Automat. Construct. 57, 249-259. doi: 10.1016/j.autcon.2015.05.002

Cosma, A. C., and Simha, R. (2019). Using the contrast within a single face heat map to assess personal thermal comfort. Build. Environ. 160:106163. doi: 10.1016/j.buildenv.2019.106163

Dalamagkidis, K., Kolokotsa, D., Kalaitzakis, K., and Stavrakakis, G. S. (2007). Reinforcement learning for energy conservation and comfort in buildings. Build. Environ. 42, 2686-2698. doi: 10.1016/j.buildenv.2006.07.010

De Dear, R., Akimoto, T., Arens, E., Brager, G., Candido, C., Cheong, K., et al. (2013). Progress in thermal comfort research over the last twenty years. Indoor Air 23, 442-461. doi: 10.1111/ina.12046

De Dear, R., and Brager, G. S. (1998). Developing an adaptive model of thermal comfort and preference. Center Built Environ. 104, 145-167.

Doukas, H., Patlitzianas, K. D., Iatropoulos, K., and Psarras, J. (2007). Intelligent building energy management system using rule sets. Build. Environ. 42, 35623569. doi: 10.1016/j.buildenv.2006.10.024

Dounis, A. I. (2010). Artificial intelligence for energy conservation in buildings. Adv. Build. Energy Res. 4, 267-299. doi: 10.3763/aber.2009.0408

Dounis, A. I., and Caraiscos, C. (2009). Advanced control systems engineering for energy and comfort management in a building environment-a review. Renew. Sustain. Energy Rev. 13, 1246-1261. doi: 10.1016/j.rser.2008.09.015

Frontczak, M., and Wargocki, P. (2011). Literature survey on how different factors influence human comfort in indoor environments. Build. Environ. 46, 922-937. doi: 10.1016/j.buildenv.2010.10.021

Ghahramani, A., Castro, G., Becerik-Gerber, B., and Yu, X. (2016a). Infrared thermography of human face for monitoring thermoregulation performance and estimating personal thermal comfort. Build. Environ. 109, 1-11. doi: 10. 1016/j.buildenv.2016.09.005

Ghahramani, A., Zhang, K., Dutta, K., and Yang, Z. B. (2016b). Becerik-Gerber, energy savings from temperature setpoints and deadband: quantifying the influence of building and system properties on savings. Appl. Energy 165, 930-942. doi: 10.1016/j.apenergy.2015.12.115

Kim, J., Zhou, Y., Schiavon, S., Raftery, P., and Brager, G. (2018). Personal comfort models: predicting individuals' thermal preference using occupant heating and cooling behavior and machine learning. Build. Environ. 129, 96-106. doi: 10.1016/j.buildenv.2017.12.011

Ghahramani, A., Castro, G., and Karvigh, S. A. B. (2018). Becerik-gerber, towards unsupervised learning of thermal comfort using infrared thermography. Appl. Energy 211, 41-49. doi: 10.1016/j.apenergy.2017.11.021
Ghahramani, A., Dutta, K., Yang, Z., Ozcelik, G., and Becerik-Gerber, B. (2015a). "Quantifying the influence of temperature setpoints, building and system features on energy consumption," in Proceedings of the Winter Simulation Conference (WSC) (Huntington Beach California: IEEE), 1000-1011.

Ghahramani, A., Tang, C., Yang, Z., and Becerik-Gerber, B. (2015b). A study of time-dependent variations in personal thermal comfort via a dynamic bayesian network. Sustain. Hum. Build. Ecosyst. 99-107. doi: 10.1061/9780784479681. 011

Ghahramani, A., and Dutta, K. B. (2018). Becerik-gerber, energy trade off analysis of optimized daily temperature setpoints. J. Build. Eng. 19, 584-591. doi: 10.1016/j.jobe.2018.06.012

Ghahramani, A., and Jazizadeh, F. B. (2014). Becerik-Gerber, A knowledge based approach for selecting energy-aware and comfort-driven HVAC temperature set points. Energy Build. 85, 536-548. doi: 10.1016/j.enbuild.2014.09.055

Ghahramani, A., and Karvigh, S. A. B. (2017). Becerik-Gerber, HVAC system energy optimization using an adaptive hybrid metaheuristic. Energy Build. 152, 149-161. doi: 10.1016/j.enbuild.2017.07.053

Ghahramani, A., Pantelic, J., Vannucci, M., Pistore, L., Liu, S., Gilligan, B., et al. (2019a). Personal CO2 bubble: context-dependent variations and wearable sensors usability. J. Build. Eng. 22, 295-304. doi: 10.1016/j.jobe.2018.11.015

Ghahramani, A., Zhu, M., Przybyla, R. J., Andersen, M. P., Galicia, P. J., Peffer, T. E., et al. (2019b). Measuring air speed with a low-power MEMS ultrasonic anemometer via adaptive phase tracking. IEEE Sens. J. 19, 8136-8145.

Ghahramani, A., and Tang, C. B. (2015). Becerik-Gerber, An online learning approach for quantifying personalized thermal comfort via adaptive stochastic modeling. Build. Environ. 92, 86-96. doi: 10.1016/j.buildenv.2015.04.017

Han, J., Jeong, Y., and Lee, I. (2011). Efficient building energy management system based on ontology, inference rules, and simulation. Sens. J. 5, 295-299.

Huizenga, C., Zhang, H., Arens, E., and Wang, D. (2004). Skin and core temperature response to partial-and whole-body heating and cooling. J. Therm. Biol. 29, 549-558. doi: 10.1016/j.jtherbio.2004.08.024

Ismail, K., and Henrìquez, J. (2001). Thermally effective windows with moving phase change material curtains. Appl. Therm. Eng. 21, 1909-1923. doi: 10.1016/ s1359-4311(01)00058-8

Jazizadeh, F., Ghahramani, A., Becerik-Gerber, B., Kichkaylo, T., and Orosz, M. (2013). Human-building interaction framework for personalized thermal comfort-driven systems in office buildings. J. Comput. Civil Eng. 28, 2-16. doi: 10.1061/(asce)cp.1943-5487.0000300

Jazizadeh, F., Ghahramani, A., Becerik-Gerber, B., Kichkaylo, T., and Orosz, M. (2014). User-led decentralized thermal comfort driven HVAC operations for improved efficiency in office buildings. Energy Build. 70, 398-410. doi: 10.1016/ j.enbuild.2013.11.066

Jazizadeh, F., and Pradeep, S. (2016). "Can computers visually quantify human thermal comfort? Short Paper," in Proceedings of the 3rd ACM International Conference on Systems for Energy-Efficient Built Environments (New York, NY: Association for Computing Machinery), 95-98. doi: 10.1145/2993422.299 3571

Jendritzky, G., and de Dear, R. (2009). “Adaptation and thermal environment,” in Biometeorology For Adaptation To Climate Variability And Change, K. L. Ebi, I. Burton, and G. R. McGregor (Dordrecht: Springer), 9-32. doi: 10.1007/978-14020-8921-3_2

Jung, W., and Jazizadeh, F. (2019). Human-in-the-loop HVAC operations: a quantitative review on occupancy, comfort, and energy-efficiency dimensions. Appl. Energy 239, 1471-1508. doi: 10.1016/j.apenergy.2019.01.070

Karjalainen, S. (2012). Thermal comfort and gender: a literature review. Indoor Air 22, 96-109. doi: 10.1111/j.1600-0668.2011.00747.x

Kates, L. (2008). Motorized Window Shade System. Washington, DC: U.S. Patent and Trademark Office.

Klepeis, N. E., Nelson, W. C., Ott, W. R., Robinson, J. P., Tsang, A. M., Switzer, P., et al. (2001). The national human activity pattern survey (NHAPS): a resource for assessing exposure to environmental pollutants. J. Exposure Analys. Environ. Epidemiol. 11, 231-252. doi: 10.1038/sj.jea.7500165

Kolokotsa, D., Rovas, D., Kosmatopoulos, E., and Kalaitzakis, K. (2011). A roadmap towards intelligent net zero-and positive-energy buildings. Solar Energy 85, 3067-3084. doi: 10.1016/j.solener.2010.09.001

Kolokotsa, D., Stavrakakis, G., Kalaitzakis, K., and Agoris, D. (2002). Genetic algorithms optimized fuzzy controller for the indoor environmental management in buildings implemented using PLC and local operating 
networks. Eng. Appl. Artif. Intellig. 15, 417-428. doi: 10.1016/s0952-1976(02) 00090-8

Korf, R. E. (2010). Artificial Intelligence Search Algorithms. London: Chapman \& Hall.

Lan, L., Lian, Z., and Pan, L. (2010). The effects of air temperature on office workers' well-being, workload and productivity-evaluated with subjective ratings. Appl. Ergonom. 42, 29-36. doi: 10.1016/j.apergo.2010.04.003

Lee, S., Bilionis, I., Karava, P., and Tzempelikos, A. (2017). A Bayesian approach for probabilistic classification and inference of occupant thermal preferences in office buildings. Build. Environ. 118, 323-343. doi: 10.1016/j.buildenv.2017. 03.009

Li, D., Menassa, C. C., and Kamat, V. R. (2017). A personalized HVAC control smartphone application framework for improved human health and well-being. Comput. Civil Eng. 2017, 82-90.

Li, D., Menassa, C. C., and Kamat, V. R. (2019). Robust non-intrusive interpretation of occupant thermal comfort in built environments with low-cost networked thermal cameras. Appl. Energy 251:113336. doi: 10.1016/j.apenergy. 2019.113336

Liu, H., Liao, J., Yang, D., Du, X., Hu, P., Yang, Y., et al. (2014). The response of human thermal perception and skin temperature to step-change transient thermal environments. Build. Environ. 73, 232-238. doi: 10.1016/j.buildenv. 2013.12.007

Luo, M., Arens, E., Zhang, H., Ghahramani, A., and Wang, Z. (2018). Thermal comfort evaluated for combinations of energy-efficient personal heating and cooling devices. Build. Environ. 143, 206-216. doi: 10.1016/j.buildenv.2018. 07.008

Luo, M., Wang, Z., Zhang, H., Arens, E., Filingeri, D., Jin, L., et al. (2019). High-density thermal sensitivity maps of the human body. Build. Environ. 167:106435. doi: 10.1016/j.buildenv.2019.106435

Marche, C., Nitti, M., and Pilloni, V. (2017). "Energy efficiency in smart building: a comfort aware approach based on social internet of thingsin," in Proceedings of the 2017 Global Internet of Things Summit (GIoTS). Piscataway, NJ.

Masoso, O., and Grobler, L. J. (2010). The dark side of occupants' behaviour on building energy use. Energy Build. 42, 173-177. doi: 10.1016/j.enbuild.2009. 08.009

Miller, C., Nagy, Z., and Schlueter, A. (2018). A review of unsupervised statistical learning and visual analytics techniques applied to performance analysis of nonresidential buildings. Renew. Sustain. Energy Rev. 81, 1365-1377. doi: 10.1016/ j.rser.2017.05.124

Mishra, A. K., and Ramgopal, M. (2013). Field studies on human thermal comfort-an overview. Build. Environ. 64, 94-106. doi: 10.1016/j.buildenv. 2013.02.015

Murakami, Y., Terano, M., Mizutani, K., Harada, M., and Kuno, S. (2007), Field experiments on energy consumption and thermal comfort in the office environment controlled by occupants' requirements from PC terminal. Build. Environ. 42, 4022-4027. doi: 10.1016/j.buildenv.2006.05.012

Newell, A., and Simon, H. A. (1972). Human Problem Solving. Englewood Cliffs, NJ: Prentice-Hall.

Ning, H., Wang, Z., and Ji, Y. (2016). Thermal history and adaptation: does a long-term indoor thermal exposure impact human thermal adaptability? Appl. Energy 183, 22-30. doi: 10.1016/j.apenergy.2016.08.157

Pasupathy, A., Velraj, R., and Seeniraj, R. (2008). Phase change material-based building architecture for thermal management in residential and commercial establishments. Renew. Sustain. Energy Rev. 12, 39-64. doi: 10.1016/j.rser.2006. 05.010

Pasut, W., Zhang, H., Arens, E., Kaam, S., and Zhai, Y. (2013). Effect of a heated and cooled office chair on thermal comfort. HVACeR Res. 19, 574-583.

Pasut, W., Zhang, H., Arens, E., and Zhai, Y. (2015). Energy-efficient comfort with a heated/cooled chair: results from human subject tests. Build. Environ. 84, 10-21. doi: 10.1016/j.buildenv.2014.10.026

Pérez-Lombard, L., Ortiz, J., and Pout, C. (2008). A review on buildings energy consumption information. Energy Build. 40, 394-398. doi: 10.1016/j.enbuild. 2007.03.007

Pienta, W. T., Coogan, J. J., and Songkakul, P. (2014). ThermostatControl Device With Integrated Feedback And Notification Capability. U.S. Patent No. $8,870,087$. Washington, DC: U.S. Patent and Trademark Office.
Provins, K. (1966). Environmental heat, body temperature and behaviour: An hypothesis 1. Austr. J. Psychol. 18, 118-129. doi: 10.1080/00049536608255722

Quinlan, J. R. (1996). "Bagging, boosting, and C4," in Proceedings of the Thirteenth National Conference On Artificial Intelligence, New York, NY.

Rafsanjani, H. N., and Ahn, C. (2016). Linking building energy-load variations with occupants' energy-use behaviors in commercial buildings: non-intrusive occupant load monitoring (NIOLM). Proc. Eng. 145, 532-539. doi: 10.1016/j. proeng.2016.04.041

Rafsanjani, H. N., Ahn, C. R., and Alahmad, M. (2015). A review of approaches for sensing, understanding, and improving occupancy-related energy-use behaviors in commercial buildings. Energies 8, 10996-11029. doi: 10.3390/ en81010996

Rafsanjani, H. N., and Ghahramani, A. (2019). Extracting occupants' energy-use patterns from Wi-Fi networks in office buildings. J. Build. Eng. 26:100864. doi: 10.1016/j.jobe.2019.100864

Rafsanjani, H. N., and Ghahramani, A. (2020). Towards utilizing internet of things (IoT) devices for understanding individual occupants' energy usage of personal and shared appliances in office buildings. J. Build. Eng. 27:100948. doi: 10.1016/ j.jobe. 2019.100948

Ranjan, J., and Scott, J. (2016). "ThermalSense: determining dynamic thermal comfort preferences using thermographic imaging," in Proceedings of the the 2016 ACM International Joint Conference, Washington, D.C.

Rantanen, J., Alfthan, N., Impio, J., Karinsalo, T., Malmivaara, M., Matala, R., et al. (2000). "Smart clothing for the arctic environment," in Proceedings of the Digest of Papers. Fourth International Symposium on Wearable Computers, Atlanta, GA.

Ray, P. P. (2016). An internet of things based approach to thermal comfort measurement and monitoring. Energy Build. 1, 1-7.

Roth, K. W., Westphalen, D., Dieckmann, J., Hamilton, S. D., and Goetzler, W. (2002). Energy Consumption Characteristics Of Commercial Building Hvac Systems Volume Iii: Energy Savings Potential. Washington, D.C: US Department of Energy.

Russell, S., Norvig, P., and Intelligence, A. (1995). A Modern Approach, Artificial Intelligence. Englewood Cliffs, NJ: Prentice-Hall.

Schellen, L., van Marken Lichtenbelt, W., Loomans, M., Toftum, J., and De Wit, M. (2010). Differences between young adults and elderly in thermal comfort, productivity, and thermal physiology in response to a moderate temperature drift and a steady-state condition. Indoor Air 20, 273-283. doi: 10.1111/j.16000668.2010.00657.x

Song, W. F., Zhang, C. J., Lai, D. D., Wang, F. M., and Kuklane, K. (2016). Use of a novel smart heating sleeping bag to improve wearers' local thermal comfort in the feet. Sci. Rep. 6:19326.

Soori, P. K., and Vishwas, M. (2013). Lighting control strategy for energy efficient office lighting system design. Energy Build. 66, 329-337. doi: 10.1016/j.enbuild. 2013.07.039

Sutton, R. S., Barto, A. G., and Bach, F. (1998). Reinforcement Learning: An Introduction. Cambridge, MA: MIT press.

Takada, S., Matsumoto, S., and Matsushita, T. (2013). Prediction of whole-body thermal sensation in the non-steady state based on skin temperature. Build. Environ. 68, 123-133. doi: 10.1016/j.buildenv.2013.06.004

Tsuzuki, K., Arens, E., Bauman, F., and Wyon, D. (1999). Individual Thermal Comfort Control With Desk-Mounted And Floor-Mounted Task/Ambient Conditioning (Tac) Systems. Berkeley: University of California.

Uğursal, A., and Culp, C. H. (2013). The effect of temperature, metabolic rate and dynamic localized airflow on thermal comfort. Appl. Energy 111, 64-73. doi: 10.1016/j.apenergy.2013.04.014

Vakiloroaya, V., Samali, B., Fakhar, A., and Pishghadam, K. (2014). A review of different strategies for HVAC energy saving. Energy Convers. Manag. 77, 738-754. doi: 10.1016/j.enconman.2013.10.023

Wang, J., Wang, Z., de Dear, R., Luo, M., Ghahramani, A., and Lin, B. (2018). The uncertainty of subjective thermal comfort measurement. Energy Build. 181, 38-49. doi: 10.1016/j.enbuild.2018.09.041

Wang, Z., de Dear, R., Luo, M., Lin, B., He, Y., Ghahramani, A., et al. (2018). Individual difference in thermal comfort: a literature review. Build. Environ. 138, 181-193. doi: 10.1016/j.buildenv.2018.04.040

Wyon, D. P., Andersen, I., and Lundqvist, G. R. (1979). The effects of moderate heat stress on mental performance. Scand. J. Work Environ. Health 5, 352-361. doi: $10.5271 /$ sjweh.2646 
Xiao, F., and Fan, C. (2014). Data mining in building automation system for improving building operational performance. Energy Build. 75, 109-118. doi: 10.1016/j.enbuild.2014.02.005

Yang, I., Yeo, M., and Kim, K. (2003). Application of artificial neural network to predict the optimal start time for heating system in building. Energy Convers. Manag. 44, 2791-2809. doi: 10.1016/s0196-8904(03)00044-x

Yang, L., Zhang, M., and Jiang, Y. (2009). A new approach for temperature control of medical air insulation blanket. Energy Build. 2, 261-263.

Yang, R., and Wang, L. (2013). Development of multi-agent system for building energy and comfort management based on occupant behaviors. Energy Build. 56, 1-7. doi: 10.1016/j.enbuild.2012.10.025

Zagreus, L., Huizenga, C., Arens, E., and Lehrer, D. (2004). Listening to the occupants: a Web-based indoor environmental quality survey. Indoor Air 14, 65-74. doi: 10.1111/j.1600-0668.2004.00301.x

Zhang, H., Arens, E., Taub, M., Dickerhoff, D., Bauman, F., Fountain, M., et al. (2015a). Using footwarmers in offices for thermal comfort and energy savings. Energy Build. 104, 233-243. doi: 10.1016/j.enbuild.2015.06.086

Zhang, H., Arens, E., and Zhai, Y. (2015b). A review of the corrective power of personal comfort systems in non-neutral ambient environments. Build. Environ. 91, 15-41. doi: 10.1016/j.buildenv.2015.03.013
Zhang, W., Hu, W., and Wen, Y. (2018). Thermal comfort modeling for smart buildings: a fine-grained deep learning approach. IEEE Internet Things J. 6, 2540-2549.

Zhao, Q., Zhao, Y., Wang, F., Wang, J., Jiang, Y., and Zhang, F. (2014). A data-driven method to describe the personalized dynamic thermal comfort in ordinary office environment: From model to application. Build. Environ. 72, 309-318. doi: 10.1016/j.buildenv.2013. 11.008

Conflict of Interest: The authors declare that this study received funding from Ingersoll rand Inc. The funder provided logistics support and high-level directions for this review.

Copyright (c) 2020 Ghahramani, Galicia, Lehrer, Varghese, Wang and Pandit. This is an open-access article distributed under the terms of the Creative Commons Attribution License (CC BY). The use, distribution or reproduction in other forums is permitted, provided the original author(s) and the copyright owner(s) are credited and that the original publication in this journal is cited, in accordance with accepted academic practice. No use, distribution or reproduction is permitted which does not comply with these terms. 